\title{
Examining the Asymmetric Behavior across the Phases of Capacity Utilization Rates in Turkey
}

\author{
Ismail Onur Baycan*
}

\author{
Faculty of Economics and Administrative Sciences, Department of Economics, Anadolu University, 26470 \\ Eskisehir, Turkey
}

\begin{abstract}
This is the first study that explicitly models and characterizes the asymmetric state dependent dynamics of the Turkish capacity utilization rates of the manufacturing industry. The analysis employs hidden Markov models to the mean and variance that are robust to potential structural breaks. The model parameters are estimated using EM algorithm together with the nonlinear filter to provide the maximum likelihood estimates without imposing any a priori restrictions on model parameters and infer the states through statistical estimation. The results reveal nonlinearity, determine the number of regimes and identify the nonlinear heteroscedasticity across different phases. The paper provides the smoothed probabilities of low, moderate and high capacity utilization regimes along with the fitted values for the Turkish capacity utilization rates. A three state specification with regime-dependent mean and variance dynamics is identified. The study also employs the estimated transition probabilities and determines the durations and persistence of staying in each particular regime for the capacity utilization rate fluctuations of the manufacturing industry in Turkey.
\end{abstract}

Keywords: Capacity Utilization Rate, Manufacturing Industry, Markov Switching Models.

\section{INTRODUCTION}

Capacity utilization rate of the manufacturing industry carries great importance for economies, especially considering its usefulness as an indicator to analyze the economic structure of a country and its value to provide a basis for forward-looking economic policies for the policymakers. Even though the economic importance of the emerging market economies has rapidly increased during the last decades, the increasing globalization of capital movements causes the emerging market economies to become more fragile in the global markets. An important solution to the increasing fragility of developing economies is the required structural transformations that are based on production. Therefore, capacity utilization rate of the manufacturing industry is an important indicator for understanding and analyzing countries' production structure, which allows for further creation of policies for growth and development.

Capacity utilization rate of the manufacturing sector has long been studied to explain the changes in the main macroeconomic variables. The study of Berndtand and Hesse (1986) computes the capacity utilization rates as the ratio of actual to capacity output and adjusts conventional measures of multifactor productivity growth for changes in capacity utilization. Their findings obtain more realistic results compared to

${ }^{*}$ Address correspondence to this author at the Faculty of Economics and Administrative Sciences, Department of Economics, Anadolu University, 26470 Eskisehir, Turkey; Tel: +90 (222) 335 0580/3228;

E-mail: iobaycan@anadolu.edu.tr the traditional procedures. Hulten (1986) decomposes the growth rate of real short-run average cost considering the capacity utilization rate as one of the components. The results show that the growth rate of real short-run average cost equals the growth rate of the false residual, and that the false and true residuals differ by the Berndt-Fuss capacity utilization effect. Palaka, Erlebacher and Kropp (1998) examine the lead-time setting for capacity utilization and show that the capacity utilization is lower when customers are more sensitive to lead-times and the firm incurs higher congestion related costs the penalty.

The literature also provides studies that employ Markov Switching framework that account for the asymmetric dynamics of the capital utilization rates for developed economies. Morley and Piger (2014) examine the comparison of model-averaged measure of the capacity utilization and business cycle that displays an asymmetric shape and reports that their asymmetric characterizations are closely related. Liu, Waggoner and Zha (2011) identify the sources of macroeconomic economic fluctuations by estimating a variety of medium-scale DSGE models within a unified framework that incorporates regime switching. Their study identify that capital utilization shocks related with productivity account for macroeconomic fluctuations more than the other economic variables. King and Rebelo (1999) report that a RBC varying capital utilization model yields realistic business cycles when small, nonnegative changes in technology are considered in the model.

The studies focusing on the capital utilization rates are rather limited for the Turkish economy. Sunal and 
Aykaç (2005) examines the relationship between employment, exports and capacity utilization of the Turkish firms using a panel cointegration method. They report the existence of a positive correlation between capacity utilization in Turkey and the other variables. Yamak and Küçükkale (2000) investigate the relationship between inflation and capacity utilization rates. Their findings document that the optimal capacity utilization level, which does not accelerate the inflation for Turkish economy, has risen during the recent years.

On the other hand, there are no studies that account for the asymmetric characterization of the Turkish capacity utilization rates for the manufacturing industry. To fulfil this gap, this is the first study that explicitly models the dynamics of capacity utilization rate fluctuations of the manufacturing industry in Turkey to reveal the characteristic properties of these fluctuations when we account for the asymmetric behavior across cyclical phases. The study employs hidden Markov models to the mean and variance at monthly frequency that are robust to potential structural breaks that may have occurred due to major shifts in policy and frequent shocks to the economy. Using this framework is useful considering the dramatic policy changes in the Turkish economy. It allows us to obtain a dynamic regime classification that is not sensitive to model specification.

The paper is organized as follows. Section two summarizes the general form of the model that is employed to identify the asymmetric dynamics of the capacity utilization rate and discusses the data. Section three presents the empirical results. Section four concludes.

\section{THE MODEL AND DATA}

The study utilizes the Markov regime switching type of models, where the Turkish capacity utilization rate of the manufacturing industry dynamics are driven by an unobservable stochastic state variable. Employing this framework allows the model parameters to take different values according to different phases of the observed variable at a given point in time.

Let $y_{t}$ stands for the Turkish capacity utilization rate that can be written as the sum of two components

$y_{t}=n_{t}+z_{t}$

where the term for the Markov trend is given with $n_{t}$ and the term for the Gaussian component is given with $z_{t}$.
The Markov trend is consists of,

$n_{t}=\alpha\left(s_{t}\right)+n_{t-1}$,

where $s_{t} \in\{1, \ldots, M\}$ is a latent Markov processes that determines the state of the economy and $\alpha\left(s_{t}\right)=\alpha_{i}$ for $s_{t}=i, i \in\{1, \ldots, M\}$.

It follows, then, the Markov regime switching dynamics formulates a probability rule for transition between states. The unobserved state variable, $s_{t}$, follows a first-order Markov-process, where the current regime depends only on the regime prevailing one period ago.

The rule of probability is given with,

$$
P\left[s_{t}=j \mid s_{t-1}=i, s_{t-2}=k, \ldots\right]=P\left[s_{t}=j \mid s=i\right]=p_{i j},
$$

the probability that state $i$ will be followed by state $j$ is indicated by $p_{i j}$ and $i, j, k \in\{1, \ldots, M\}$. By rules of probability, we have $\sum_{j=1}^{M} p_{i j}=1$.

The second term in Equation (2), which is the Gaussian component, is given by:

$z_{t}=z_{t-1}+\phi_{1}\left(z_{t-1}-z_{t-2}\right)+\cdots+\phi_{r}\left(z_{t-r}-z_{t-r-1}\right)+\varepsilon_{t}$

where $\varepsilon_{t} / \sigma\left(s_{t}\right) \sim \boldsymbol{N I D}(0,1)$ and is independent of $\boldsymbol{n}_{\boldsymbol{t}+\boldsymbol{h}}, \quad \forall \boldsymbol{h} \geq 0 .{ }^{1}$ By differencing Equation (1) and substituting (4) we obtain,

$\Delta y_{t}=a\left(s_{t}\right)+\phi_{1}\left(z_{t-1}-z_{t-2}\right)+\cdots+\phi_{r}\left(z_{t-r}-z_{t-r-1}\right)+\varepsilon_{t}$

This model is able to identify regimes characterized by different means and variances. Considering the major policy changes in Turkey that may cause structural breaks in the capacity utilization rate, the study uses a hidden Markov specification where the autoregressive terms in Equation (4) are set to zero ${ }^{2}$.

The differenced series becomes,

$\Delta y_{t}=\alpha\left(s_{t}\right)+\varepsilon_{t}$.

${ }^{1}$ Note that this is the general form of the model. Under constant variance assumption, the model boils down to a mean-switching only specification.

${ }^{2}$ See Chauvet (2002) for an application on Brazilian economy. 
Following Hamilton (1990), we estimate the models using EM algorithm together with the nonlinear filter to find the maximum likelihood estimates of the model parameters. Note that we do not impose any a priori restrictions on model parameters and infer the states through statistical estimation. See Dempster, Laird and Rubin (1987) for a detailed description of the EM algorithm and Krolzig (1997) for its application to MS class of models.

The data set consists of seasonally adjusted monthly Turkish capacity utilization rate of the manufacturing industry from February 1991 to August 2015. The data sets are drawn from the statistical database of the Turkish Central Bank. Following Stock and Watson (2005), high frequency movements in the different series of Turkish capacity utilization rate are smoothed out by taking twelve-month averages of the annual month-to-month growth rates. Year on year growth rates are calculated for monthly frequencies, i.e., $\Delta I P I_{t}=100\left[\ln \left(I P I_{t}\right)-\ln \left(I P I_{t-12}\right)\right]$.

\section{EMPIRICAL RESULTS}

The study first examines the presence of unit roots in the Turkish capacity utilization rate of the manufacturing industry data with the Augmented Dickey-Fuller test proposed in Dickey and Fuller (1981) and the Phillips Perron proposed in Phillips Perron (1998). Stationarity is achieved after taking twelvemonth averages of the annual month-to-month growth rates of the Turkish capacity utilization rate. Table 1 presents the results of the unit root tests. The results reject the unit root hypothesis both with the ADF and PP tests.

Table 1: Unit Root Tests for the Capacity Utilization Rate of the Manufacturing Industry

\begin{tabular}{|c|c|c|}
\hline Test & Test Statistic & $\begin{array}{c}\text { Critical Value } \\
\mathbf{1 \%}\end{array}$ \\
\hline \hline ADF & -4.916313 & -3.453400 \\
\hline PP & -5.078659 & \\
\hline
\end{tabular}

Note: ADF and PP denote the Augmented Dickey Fuller and Phillips Perron tests. Lags used in the computation of statistics are automatically chosen by Eviews with respect to SIC criterion. The asymptotically equivalent critical values for the test statistics are taken from MacKinnon (1996).

To reveal the characteristics of different phases of the Turkish capacity utilization rate of the manufacturing industry and provide insight about its dynamics, we first examine nonlinearity, determine the number of regimes and identify the regime dependent variance. Likelihood ratio and several information criteria tests are employed to identify the number of states and to examine heteroscedasticity to identify whether or not the variance structure also switches with respect to different regimes. We also test the null hypothesis of linearity against the alternative of nonlinear Markov switching specifications.

Table 2 presents regime dependent maximum likelihood mean and variance estimations of the selected models, transition probabilities, AIC, HQ and SIC penalized likelihood model selection criteria tests, Likelihood Ratio statistics, and the Davies upper bound $p$-values for the Turkish capacity utilization rates. The numbers in parenthesis give the asymptotic standard errors. Figure 1 provides the sequence of the smoothed probabilities for each different regime along with the fitted values for the Turkish capacity utilization rates

Table 2: $\operatorname{MSMH(3)}$ - AR(0) Results for Monthly Turkish Capacity Utilization Rate of the Manufacturing Industry

\begin{tabular}{|c|c|}
\hline & Turkish Capacity Utilization Rate \\
\hline $\log -\mathrm{L}$ & -538.903302 \\
\hline LRP & 0.000 \\
\hline$\alpha_{0}$ & $\begin{array}{c}-4.26438 \\
(0.4115)\end{array}$ \\
\hline$\alpha_{1}$ & $\begin{array}{l}-0.204138 \\
(0.09279)\end{array}$ \\
\hline$\alpha_{2}$ & $\begin{array}{l}2.11005 \\
(0.1727)\end{array}$ \\
\hline$\sigma_{0}$ & $\begin{array}{l}2.58745 \\
(0.2665)\end{array}$ \\
\hline$\sigma_{1}$ & $\begin{array}{l}0.895394 \\
(0.06855)\end{array}$ \\
\hline$\sigma_{2}$ & $\begin{array}{l}1.58568 \\
(0.1133)\end{array}$ \\
\hline$p_{00}$ & $\begin{array}{l}0.918587 \\
(0.03923)\end{array}$ \\
\hline$p_{01}$ & $\begin{array}{c}0.0334544 \\
(0.01654)\end{array}$ \\
\hline$p_{11}$ & $\begin{array}{l}0.944399 \\
(0.02335)\end{array}$ \\
\hline$p_{12}$ & $\begin{array}{c}0.0651236 \\
(0.02584)\end{array}$ \\
\hline AIC & 3.8792 \\
\hline SC & 4.0080 \\
\hline $\mathrm{HQ}$ & 3.9308 \\
\hline
\end{tabular}

Notes: The sample period is January 1991 - August 2015. LRP denotes the upper bound for the p-value of the likelihood ratio test of linearity based on Davies (1987). Standard errors are reported in parenthesis. 


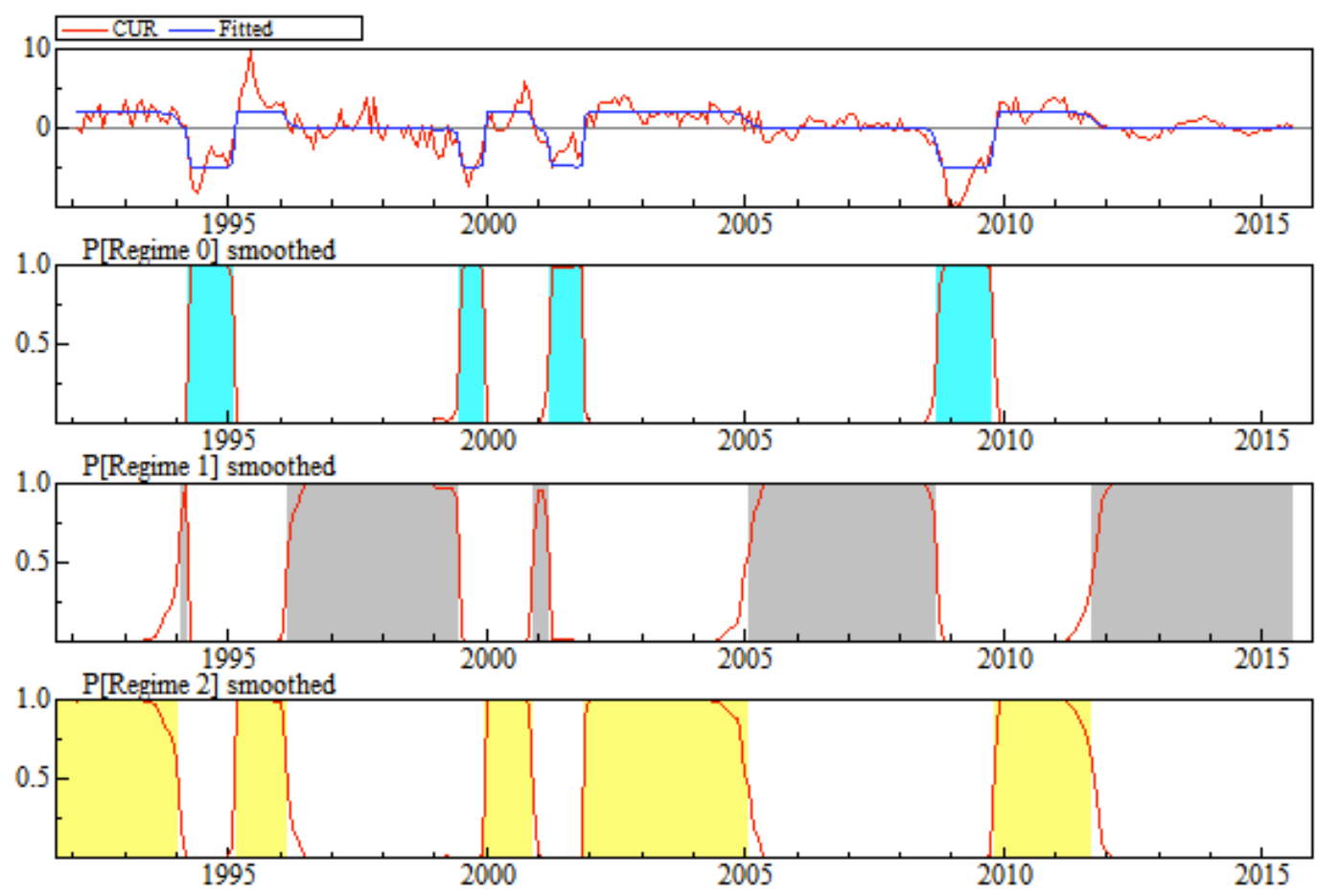

Figure 1: Smoothed Probabilities of Low, Moderate and High Capacity Utilization States, and Fitted Values.

Linearity is rejected in favor of the regime switching nonlinear model. The strong asymmetry is evident in the small value of the Davies upper bound and in the substantially different estimates and regime probabilities across the states. The smoothed probabilities of the low utilization regime with respect to the fluctuations of the manufacturing industry identify four spikes in probabilities which are all associated with sharp declines in the capacity utilization rates. These smoothed probabilities for the state of low capacity utilization growth show close association with the Turkish economic crises for the sample period.

Regarding determining the number of regimes, the information criteria tests and modified likelihood ratio values comparing a three state versus a two state specification suggest that a three-state specification captures the state dependent dynamics of the capacity utilization rate of the manufacturing industry better than a two state specification. A three state specification with regime-dependent dynamics is identified to obtain a convenient framework as it decomposes the non-low capacity utilization state into moderate utilization and high utilization states for the capacity utilization rate fluctuations of the manufacturing industry in Turkey.

We next employ the same specification tests to examine the dynamics for nonlinear heteroscedasticity for the capacity utilization rates of Turkey. The results are in favor of regime dependent variances. The estimated variances of the low capacity utilization regime are higher than the variances of moderate and high capacity utilization regimes. These results document that the low capacity utilization regimes are the most volatile regimes compared to the moderate and high capacity utilization regimes.

The study also employs the estimated transition probabilities to determine the duration and persistence of staying in a particular regime for the Turkish capacity utilization rate. The Markov transition probabilities of being in the same state both in the current and the previous periods are given in Table 3 .

Table 3: Estimated Markov Probabilities of Staying in the same State

\begin{tabular}{|c|c|}
\hline & CUR \\
\hline \hline Regime 0 & 0.91859 \\
\hline Regime 1 & 0.94440 \\
\hline Regime 2 & 0.93488 \\
\hline
\end{tabular}

Note: Regime 0 represents the low capacity utilization, Regime 1 represents the moderate capacity utilization, regime 2 represents the high capacity utilization.

Following Kim and Nelson (2003), calculation of the expected duration of each state can be calculated with the following equations: 


$$
E\left(D_{j}\right)=\frac{1}{1-p_{j j}}
$$

The expected duration of the low capacity utilization regime $\left(s_{t}=0\right)$, moderate capacity utilization regime $\left(s_{t}=1\right)$, and the high capacity utilization regime $\left(s_{t}=2\right)$ are given as follows:

$$
\begin{aligned}
& E\left(D_{0}\right)=\frac{1}{1-p_{00}} \\
& E\left(D_{1}\right)=\frac{1}{1-p_{11}} \\
& E\left(D_{2}\right)=\frac{1}{1-p_{22}}
\end{aligned}
$$

Table 4: Average Durations and Percentages of Staying in One State

\begin{tabular}{|c|c|c|}
\hline \multirow{2}{*}{} & \multicolumn{2}{|c|}{ CUR } \\
\cline { 2 - 3 } & Percentage & Average Duration \\
\hline \hline Regime 0 & $18.37 \%$ & 13.00 \\
\hline Regime 1 & $43.82 \%$ & 15.50 \\
\hline Regime 2 & $37.81 \%$ & 15.29 \\
\hline
\end{tabular}

Note: Regime 0 represents the low capacity utilization, Regime 1 represents the moderate capacity utilization, regime 2 represents the high capacity utilization.

The capacity utilization rate for Turkey has a monthly growth rate of around $-4.26 \%$ from the same month of the previous year in a low capacity utilization regime. Once the economy is in the low capacity utilization regime, the probability of staying in this regime for the next month is 0.91 . This implies an average duration of 13 months for the low utilization regime, which corresponds to $18.37 \%$ of the sample period. The monthly mean growth rate of the moderate capacity utilization rate is around $-0.20 \%$ for state 1 , which has an expected duration of 15.50 months as implied by the 0.94 transition probability estimate of staying in this regime once it prevails. The manufacturing industry stays in the moderate capital utilization state $43.82 \%$ of the time. Among the three different regimes, the moderate capital utilization regime has the longest average duration and persistence. The Turkish manufacturing sector has a monthly growth rate of around $2.11 \%$ in a typical high capital utilization state. Once the economy enters into the high capital utilization regime, the probability of staying in the high capital utilization regime for the next month is 0.93 . This implies an average duration of 15.29 months for the high utilization state, which corresponds to $37.81 \%$ of the whole time.

\section{CONCLUSION}

Capacity utilization rate of the manufacturing industry is an important indicator to understand and analyze a country's production structure by allowing for further creation of policies for growth and development. This study models the state dependent dynamics and accounts for the asymmetric behavior of the Turkish capacity utilization rate across different phases and provide further insights about capacity utilization rate of the manufacturing industry. The results characterize the state dependent dynamics across different utilization regimes. Hidden Markov models are employed to the mean and variance at monthly frequency that are robust to potential structural breaks that may have occurred due to major shifts in policy and frequent shocks to the economy. The study estimates the model parameters using EM algorithm together with the nonlinear filter to find the maximum likelihood estimates without imposing any a priori restrictions on model parameters and infer the states through statistical estimation. Considering the previous studies in the literature, which do not account for the asymmetric characterization of the Turkish capacity utilization rates for the manufacturing industry, the results identify the importance of modeling nonlinear specifications for analyzing the capacity utilization rates in Turkey. The data set consists of seasonally adjusted monthly Turkish capacity utilization rate of the manufacturing industry from February 1991 to August 2015. Turkish capacity utilization rate is smoothed out by taking twelve-month averages of the annual monthto-month growth rates. To reveal the characteristics of different phases of the Turkish capacity utilization rate of the manufacturing industry and provide insight about its dynamics, the study examines nonlinearity, determines the number of regimes and identifies the regime dependent variances. Instead of the commonly employed two state specifications in the framework, the study employs a three state specification to decompose the regimes other than the low capital utilization state into moderate capital utilization and high capital utilization states. This enables us to capture the state dependent dynamics and analyze the asymmetric behavior of Turkish capital utilization even further and to compare the characteristics of different phases of the manufacturing industry. Considering the regime dependent heteroscedasticity, low capital utilization regimes are found to be the most volatile state in the 
manufacturing industry. The results provide the smoothed probability sequences for each different regime along with the fitted values for the Turkish capacity utilization rates. The study also employs the estimated transition probabilities and determines the duration and persistence of staying in each particular regime for the Turkish capacity utilization rates.

\section{REFERENCES}

Berndt, E. R., \& Hesse, D. M. (1986). Measuring and assessing capacity utilization in the manufacturing sectors of nine OECD countries. European Economic Review, 30(5), 961989.

http://dx.doi.org/10.1016/S0014-2921(86)80001-0

Chauvet, M. (2002). The Brazilian business and growth cycles. Revista Brasileira de Economia, 56(1), 75-106. http://dx.doi.org/10.1590/S0034-71402002000100003

Davies, R. B. (1987). Hypothesis testing when a nuisance parameter is present only under the alternative. Biometrika, 74(1), 3343.

Dempster, A. P., Laird, N. M., \& Rubin, D. B. (1977). Maximum likelihood from incomplete data via the EM algorithm. Journal of the Royal Statistical Society. Series B (Methodological), 138.

Dickey, David A., \&Wayne A. Fuller. "Likelihood Ratio Statistics for Autoregressive Time Series with a Unit Root." Econometrica: Journal of the Econometric Society (1981): 1057-1072. http://dx.doi.org/10.2307/1912517

Hamilton, J. D. (1990). Analysis of time series subject to changes in regime. Journal of econometrics, 45(1), 39-70. http://dx.doi.org/10.1016/0304-4076(90)90093-9

Hulten, C. R. (1986). Productivity change, capacity utilization, and the sources of efficiency growth. Journal of econometrics, 33(1), 31-50.

http://dx.doi.org/10.1016/0304-4076(86)90026-6
Kim, C.-J., \& Nelson, C. R. (1999). Has the US economy become more stable? A Bayesian approach based on a Markovswitching model of the business cycle. Review of Economics and Statistics, 81(4), 608-616.

http://dx.doi.org/10.1162/003465399558472

King, R. G., \& Rebelo, S. T. (1999). Resuscitating real business cycles. Handbook of macroeconomics, 1, 927-1007. http://dx.doi.org/10.1016/S1574-0048(99)10022-3

Krolzig, H.-M. (1997). Markov-switching vector autoregressions (modelling, statistical interference, and application to business cycle analysis). Lecture notes in economics and mathematical systems.

Liu, Z., Waggoner, D. F., \& Zha, T. (2011). Sources of macroeconomic fluctuations: A regime-switching DSGE approach. Quantitative Economics,2(2), 251-301. http://dx.doi.org/10.3982/QE71

Morley, J., \& Piger, J. (2012). The asymmetric business cycle. Review of Economics and Statistics, 94(1), 208-221 http://dx.doi.org/10.1162/REST_a_00169

Phillips, Peter CB, \& Pierre Perron. "Testing for a Unit Root in Time Series Regression." Biometrika 75, no. 2 (1988): 335-346. http://dx.doi.org/10.1093/biomet/75.2.335

Palaka, K., Erlebacher, S., \& Kropp, D. H. (1998). Lead-time setting, capacity utilization, and pricing decisions under lead-time dependent demand. lie Transactions, 30(2), 151-163. http://dx.doi.org/10.1080/07408179808966447

Stock, James H., \& Mark W. Watson. "Understanding Changes in International Business Cycle Dynamics." Journal of the European Economic Association 3, no. 5 (2005): 968-1006. http://dx.doi.org/10.1162/1542476054729446

Sunal, S., \& Aykaç, E. (2005). Türk İmalat Sanayinde İstihdam, İhracat Ve Kapasite Kullanım Oranı İlişkisi: Panel Koentegrasyon. VII National Econometrics and Statistics Symposium, 1-24.

Received on 18-09-2015

Accepted on 07-10-2015

Published on 22-10-2015

DOI: http://dx.doi.org/10.6000/1929-7092.2015.04.16

(C) 2015 Ismail Onur Baycan; Licensee Lifescience Global.

This is an open access article licensed under the terms of the Creative Commons Attribution Non-Commercial License (http://creativecommons.org/licenses/by-nc/3.0/) which permits unrestricted, non-commercial use, distribution and reproduction in any medium, provided the work is properly cited. 